\title{
General practitioner certification
}

\author{
José Adrián Rojas-Dosal
}

Chairman, Comité Normativo Nacional de Medicina General (CONAMEGE), Mexico

The regulation of the medical profession is a longstanding process in our country. Since the times of the viceroyalty there was the Real Tribunal del Protomedicato, the function of which was to examine physicians, surgeons and pharmacists in order to be authorized to practice their profession; over time, this task went on being relegated to other administrative structures that were gradually modified, but that preserved it in force.

More recently, in the decade of 1970, the National Academy of Medicine led an entire process intended to establish specialist physicians' certification, which was highly successful and that currently enables specialist physicians' certification through their Councils.

Given the success attained in this subject, in the year of 1997, Dr. Octavio Rivero Serrano, who at that moment was the secretary of the Public Health General Council, considered it to be convenient to design a similar procedure in order to carry out a certification process for general practitioners, with the purpose to achieve an improvement in the quality and safety of patient care, by means of training and updating this important group of professionals, since they had not equivalent process available.

He called the National Academy of Medicine and the Mexican Academy of Surgery in order for the general practitioners' certification process to be designed and organized, given the experience these institutions had acquired with specialist physicians' certification, and this way guarantee the Mexican society that general practitioners also met the necessary requirements to provide quality medical care.

The necessary agreements and the commitment of all organizations that were to participate in the certification process were able to be established. The organization of state councils at each one of the states, which were to be dependent of the National Council, in order for this way facilitate the localization of practicing doctors at each state, was considered to be important.

Finally, the National General Medicine Regulatory Committee (CONAMEGE - Comité Normativo Nacional de Medicina General) was established, which was composed of representatives of the National Academy of Medicine, the Mexican Academy of Surgery, the National General Medicine Certification Council and, as external adviser, the Mexican Association of Faculties and Schools of Medicine; this institution started operating in the year 2001.

The primary objective of this organization is the certification of general practitioners from the entire country by means of an assessment of their knowledge and competences, in addition to promoting for this certification to maintain its validity in 5-year periods, which is achieved by accrediting continuing medical education.

The certification process is voluntary for general practitioners; it implies values, ethics and professionalism on their behalf, by creating awareness that it is indispensable for their patients to be ensured that they are qualified to offer them quality care, given that the certification demonstrates that they are updated as regards their knowledge and skills.

With respect to recertification, the rapid evolution of knowledge and technology undoubtedly makes that things that were regarded as being true soon become obsolete, and hence the need to maintain an update of knowledge that can be demonstrable.

Another important task also taken care of by CONAMEGE is the evaluation and scoring of courses offered to general practitioners by means of the Continuing Medical Education Subcommittee. It should be taken into account that not all courses made available to general practitioners are focused on their needs or have the necessary quality, since some of them have biases with advertising purposes or pharmaceutical
Correspondence:

José Adrián Rojas-Dosal

E-mail: adrianrojasd@prodigy.net.mx
Date of reception: 04-10-2017

Date of acceptance: 05-10-2017

DOI://dx.doi.org/10.24875/GMM.M18000051
Gac Med Mex. 2017;153:586-587

Contents available at PubMed www.gacetamedicademexico.com 
products' promotion and this is why primary care-targeted courses, with subjects on prevention and management of the most common ailments in the Mexican population are valued higher, with better scores, in addition to taking into account the educational institutions that endorse them, the organization of the entire educational process and the participation of renowned academics.

As examples of updating opportunities, the National Academy of Medicine has made the recently updated PRONADAMEG course available to all physicians, which can be taken online. The Mexican Academy of Surgery has an updating diploma course at its facilities and online, and there are other health and educational institutions, as well as medical societies, that permanently offer updating courses on different subjects.

Currently, there is the registry of 30,095 certified general practitioners, who maintain their certification valid. Although there is no reliable figure available on the number of general practitioners who practice their professional activity in our country, it is a considerable number that is close to at least $30 \%$ of them all.

The reasons why a general practitioner should be certified are based on several arguments. The first one is to demonstrate that he/she has the knowledge and skills to provide quality care to patients who trustfully put their health, and sometimes their life, in his/her hands. He/she also has to demonstrate that he/she keeps updated throughout his/her entire professional life, given that the rapid evolution of knowledge and technology forces for his/her knowledge and skills to be kept current.
The certification is also a mechanism that enables making the competences a physician must possess at the conclusion of his/her professional training comparable. Currently, there are 162 identified operating medical schools, distributed across the entire national territory, where nearly 20,000 physicians are graduating every year. Not all these schools have the necessary accreditation and, therefore, the curriculums they impart are not known, which gives rise to great disparity as regards knowledge and quality of graduates from these educational institutions. In this sense, a certification exam can palliate some deficiencies.

One more reason is that, somewhat frequently, in the working market, official or private health institutions, as well as educational institutions demand certification for hiring. One example is the Faculty of Medicine of the National Autonomous University of Mexico, where the Criteria for the Medical Degree Program Academic Personnel Evaluation consider that for the hiring of teachers for clinical cycles, teaching can be in charge of a certified general practitioner until the fifth semester.

On the other hand, the General Public Health Council has recently established an award to medical merit directed to general practitioners, which carries the name of Doctor Miguel Francisco Jiménez, for those who have stood up on their work in primary healthcare, and it would be desirable for it to be awarded to a certified physician.

Finally, the National Academy of Medicine, setting an example of congruence, has chairs available for general practitioners who meet the requirements, including having their certification current, to occupy them. 